REVIEW

\title{
Intra-articular treatments in osteoarthritis: from the symptomatic to the structure modifying
}

\section{Gossec, M Dougados}

Ann Rheum Dis 2004;63:478-482. doi: 10.1136/ard.2003.013771

The symptomatic and structural efficacy of intra-articular (IA) injections is reviewed. IA corticosteroid injections are rapidly effective, but their symptomatic benefit is short lived. Hyaluronan has delayed onset of efficacy but its benefit for pain may be longer lasting. Lavage and debridement are probably not as efficacious as once thought in osteoarthritis.

See end of article for authors' affiliations

Correspondence to: Dr L Gossec, 27 rue du Fbg, St Jacques, Paris 75014, France; laure.gossec@ cch.ap-hop-paris.fr

Accepted 24 September 2003 ntra-articular (IA) treatments for osteoarthritis (OA) have become standard because of their symptomatic effect. We examine whether some of them may have a structural effecteither deleterious as has been proposed for repeated corticosteroid injections, or beneficial as has been proposed for hyaluronan acid injections.

We also examine the symptomatic effects of the main IA treatments and ask, "Do they work?", "When does the effect start and how long is it maintained?", and "Are there known predisposing factors of efficacy?".

Owing to lack of space, the techniques and risks of IA treatments are not discussed.

\section{SYMPTOMATIC EFFECTS OF IA TREATMENTS}

Intra-articular corticosteroid treatment in OA

Intra-articular steroids are recommended in several guidelines for the management of patients with peripheral joint OA. ${ }^{12}$ They are widely used; a survey of rheumatologists in the United States suggested that more than $95 \%$ use them at least sometimes and 53\% frequently. ${ }^{3}$

\section{Level of evidence of symptomatic efficacy} Table 1 summarises the evidence for the efficacy of IA steroids in OA, which is mostly confined to the knee. ${ }^{45}$ Kirwan and Rankin reviewed 10 clinical trials, and found that the IA injection of glucocorticoids into the knee (one trial used four injections, the others used single injections) provided some additional pain relief compared with placebo treatment. ${ }^{17}$ However, there were no significant differences between treatment groups after more than l week of follow up. Ayral reviewed eight clinical trials published before October 2001, assessing IA steroids versus placebo. ${ }^{5}$ Except for the two earliest studies, patients received a single corticosteroid injection. The steroids studied were hydrocortisone, prednisolone, triamcinolone hexacetonide, methylprednisolone, and cortivazol. These drugs have not been compared with one another. The clinical assessment of efficacy was pain relief, and there was conclusive evidence that IA steroid injections are effective, but that their benefit over placebo may be relatively short lived, lasting only from 1 to 4 weeks. Finally, a third article reviewed controlled studies of treatments in knee OA published before $1995(\mathrm{n}=5) .{ }^{18}$ When a quality rating system was used, critical analysis showed that none of the studies achieved a score for design of more than 3 out of a possible 8 . The review concluded that IA steroids were better than placebo in short term efficacy $(<1$ month). Very recently, Raynauld et al evaluated repeated IA steroid injections in 68 patients with OA. ${ }^{16}$ Patients received IA triamcinolone hexacetonide $40 \mathrm{mg}$ (34 patients) or saline (34 patients) in the target knee every 3 months for up to 2 years. The knees injected with steroid showed only a trend towards greater symptom improvement at 1 year for the WOMAC (Western Ontario and McMaster Universities Osteoarthritis Index) pain subscale, night pain, and range of motion. Area under the curve analyses were used to show that knee pain and stiffness were significantly improved throughout the 2 year study by the steroid injections.

To conclude, evidence of the efficacy of IA steroids in OA is based on somewhat contradictory data and results are difficult to interpret, in particular because of a powerful response to placebo. In one study, for example, both placebo and treated groups showed a significant decrease in pain from week 1 to the final assessment at week 8. ${ }^{9}$ The effect of simple aspiration of the joint (a procedure coupled with IA steroid injections in all studies) is unknown.

"The efficacy of IA steroids is difficult to determine because patients also respond well to placebo"

Data on joints outside the knee are limited. Small studies have indicated efficacy in rhizarthrosis (trapezometacarpal joint). A prospective, open study of hip IA steroid and local anaesthetic injection ( $80 \mathrm{mg}$ methylprednisolone and $4 \mathrm{ml}$ $1 \%$ lignocaine) in 45 patients, 27 of whom had $\mathrm{OA}$, found a significant reduction in pain at 2 and 12 weeks, although the effect was lost by 26 weeks. $^{19}$

Abbreviations: $H A$, hyaluronic acid; IA, intra-articular NSAIDs, non-steroidal anti-inflammatory drugs; OA, osteoarthritis; RCT, randomised controlled trial; WOMAC, Western Ontario and McMaster Universities Osteoarthritis Index 
Table 1 Controlled trials of IA steroids in OA: symptomatic effect

\begin{tabular}{|c|c|c|c|c|c|}
\hline Author & Intervention & No & Design & Duration (weeks) & Efficacy \\
\hline Miller $1958^{\circ}$ & $\begin{array}{l}\text { HC } 50 \mathrm{mg} \text { v } \mathrm{PCB} \text { or novocaine or } \\
\text { lactic acid or feigned injection }\end{array}$ & 202 & Parallel & 24 & Equal at weeks 6 and 24 \\
\hline Wright $1960^{7}$ & $\mathrm{HC} 25 \mathrm{mg} v \mathrm{PCB}$ or HC.TBA & 25 & Crossover & 4 & $\begin{array}{l}\text { Week 2: } \mathrm{HC}=\mathrm{PCB}, \mathrm{HC} . \mathrm{TBA}>\mathrm{PCB} \text {; } \\
\text { week 4: all equal }\end{array}$ \\
\hline Cederlof $1966^{8}$ & Prednisolone $25 \mathrm{mg} \vee \mathrm{PCB}$ & 44 & Parallel & 8 & Equal at weeks $1,3,8$ \\
\hline Friedman $1980^{\circ}$ & TH $20 \mathrm{mg} v \mathrm{PCB}$ & 34 & Parallel & 8 & $\mathrm{TH}>\mathrm{PCB}$ at week 1 only \\
\hline Dieppe $1980^{10}$ & $\mathrm{TH} 20 \mathrm{mg} v \mathrm{PCB}$ & $12+16$ & Parallel/cross-over & 6 and 2 & $\mathrm{TH}>\mathrm{PCB}$ at 2 weeks only \\
\hline Valtonen $1981^{11}$ & TH $20 \mathrm{mg} v$ betamethasone $6 \mathrm{mg}$ & 42 & Parallel & 24 & $\mathrm{TH}>$ betamethasone \\
\hline Sambrook $1989^{12}$ & MP $80 \mathrm{mg}$ v $80 \mathrm{mg}$ peripatellar & 38 & Parallel & 12 & Equal \\
\hline Gaffney $1995^{13}$ & TH $20 \mathrm{mg} v \mathrm{PCB}$ & 84 & Parallel & 6 & $\mathrm{TH}>\mathrm{PCB}$ at week 1 only \\
\hline Jones $1996^{14}$ & $M P 40 \mathrm{mg} \vee \mathrm{PCB}$ & 59 & Crossover & 8 & $\mathrm{MP}>\mathrm{PCB}$ at 3 weeks only \\
\hline Ravaud $1999^{15}$ & $\begin{array}{l}\text { Cortivazol } 3.75 \mathrm{mg} \text { v } \mathrm{PCB} \text {, lavage } \\
\text { or lavage+cortivazol }\end{array}$ & 98 & Parallel, $2 \times 2$ factorial & 24 & Cortivazol $>P C B$ at week 4 only \\
\hline Raynauld $2003^{16}$ & $\begin{array}{l}\text { TH } 40 \mathrm{mg} v \text { PCB: repeated } \\
\text { injections every } 3 \text { months for } 2 \text { years }\end{array}$ & 68 & Parallel & 96 & $\begin{array}{l}\text { Trend towards greater symptom } \\
\text { improvement at } 1 \text { year, for the } \\
\text { WOMAC pain subscale, night pain, } \\
\text { and range of motion }\end{array}$ \\
\hline
\end{tabular}

Time to onset of efficacy and carryover effect

Onset of efficacy is rapid: $24-48$ hours. Maximal efficacy is reached in less than 1 week but lasts only from 1 to 4 weeks.

\section{Predisposing factors of response}

There is some discordance between the modest and short lived benefits over placebo seen in controlled studies and the clinical experience of most rheumatologists that some patients achieve a significant and sustained response. Is it possible to predict those subjects who will respond?

The presence of effusion, whether detected clinically or by ability to aspirate fluid at the time of injection, has been reported by Gaffney et al in a single blind trial $(n=84)$ to predict greater benefit from steroids. ${ }^{13}$ One trial in 147 patients with rheumatoid arthritis found a significantly reduced relapse in the group treated with complete synovial fluid aspiration before triamcinolone hexacetonide injection compared with the group without aspiration..$^{20}$ A reason why joint effusion may correlate with better response to IA steroids might be simply a truly IA injection: Jones et al reported in a contrast radiography study that one third of knee injections were extra-articular or uncertain and that aspiration of synovial fluid was associated with improved accuracy. ${ }^{21}$

By contrast an analysis by Jones and Doherty, examining a range of factors including function, psychosocial and disease related features using logistic regression, failed to relate patient response to IA steroids to any of the baseline variables, including the presence of a joint effusion. ${ }^{14}$ However, in that study, a significant predictor might have been missed owing to the small sample size (only 59 patients with knee OA were included). Friedman and Moore also found that the efficacy of steroids was not related to the presence or absence of knee effusion. ${ }^{9}$

\section{"Knee effusion may indicate inflammatory synovitis and justifies IA injection of steroids"}

There is limited evidence that the presence of hydarthrodial effusion is a predisposing factor for a better response to the IA injection of steroids. However, in our opinion, knee effusion may reflect the presence of inflammatory synovitis, justifying the IA injection of steroids.

Radiographic severity, duration of symptoms, ${ }^{13}$ presence of crystals, and raised synovial fluid cell count ${ }^{9}$ do not predict response in the knee joint. At the hip, it has been suggested that patients with an atrophic pattern respond less well than those with a hypertrophic or mixed type pattern. ${ }^{19}$

\section{Hyaluronic acid injections}

Viscosupplementation refers to the IA injection of hyaluronic acid (HA), a high molecular weight polysaccharide which is a major component of synovial fluid and cartilage, in order to relieve pain and improve function. In OA, the molecular weight and concentration of HA are diminished. The concept of viscosupplementation is based on the hypothesis that IA injections of HA could help restore the viscoelasticity of the synovial fluid and promote the endogenous synthesis of a higher molecular weight and possibly more functional hyaluronan, thereby improving mobility and articular function, and reducing pain. Several HA preparations are currently available, in two categories: low molecular weight (0.5-2 MDa) and high molecular weight (crosslinked HA, 6-7 $\mathrm{MDa})$.

\section{Level of evidence of symptomatic efficacy \\ Hyaluronan versus placebo}

Published reports include three systematic reviews and one additional randomised controlled trial (RCT) comparing hyaluronan preparations with placebo. ${ }^{517}{ }^{18}$ Most studies in humans have been carried out in patients with knee OA. The first review identified 10 RCTs of hyaluronan in the knee joint and found slightly greater benefit versus placebo for 1 to 6 months after treatment. ${ }^{17}$ The second review (nine RCTs) concluded that biological agents were better than placebo and well tolerated over a mean follow up of 48 weeks. ${ }^{18}$ The third review evaluated separately the different hyaluronan preparations. ${ }^{5}$ Hyalgan was found to be more effective than placebo for pain in eight of nine RCTs, but also for function in three RCTs, and for reducing the need for IA steroid injections in a 1 year trial. The three RCTs assessing Synvisc also found that IA steroid injections were better than placebo. The results for the efficacy of Artz compared with placebo are more contrasted. Since publication of the previous reviews, one further RCT by Brandt et al has evaluated Orthovisc compared with physiological saline in 226 patients $^{22}$ and concluded that Orthovisc was well tolerated and more effective than control in patients with a mild to moderate pain at baseline.

\section{Hyaluronan versus corticosteroid injections}

In a systematic review comparing Hyalgan with various steroids, Ayral found five RCTs reporting similar benefits of 
HA and steroids at one month, but with superiority of Hyalgan after a few months. ${ }^{5}$

Hyaluronan versus non-steroidal anti-inflammatory drugs (NSAIDs)

Three RCTs (reviewed by Ayral ${ }^{5}$ ) comparing hyaluronan with NSAIDs found that the benefit obtained with hyaluronan was similar to that of NSAIDs for pain, and with fewer gastrointestinal adverse effects.

Joints other than the knee

Three studies, one evaluating IA HA in the shoulder and two in the hip, have reported efficacy on symptoms and duration of improvement comparable with that described in the knee. ${ }^{23-25}$

\section{Time to onset of efficacy and carryover effect}

Most studies agree that onset of efficacy is delayed by $2-$ 5 weeks, the plateau of efficacy is reached in 1-2 months, and efficacy is maintained for 4-12 months.

\section{Predisposing factors of response}

Clinical predictive factors of hyaluronan efficacy have not been specifically evaluated in prospective clinical trials. In a subgroup analysis of a Hyalgan study, Altman and Moskowitz found that neither age nor level of pain were associated with the level of response to HA. ${ }^{26}$ A Canadian retrospective study of 336 patients with knee OA found that the efficacy of Hylan GF-20 was reduced in patients with effusion before the first Hylan injection, in that percentages of "better" patients were the same (70\%), but more patients were "much worse" (7.3\% v $1.1 \%$ without initial effusion). ${ }^{27}$ Radiographic predictive factors of hyaluronan efficacy have been evaluated in one prospective clinical trial, indicating that clinical improvement after IA viscosupplementation (in pain, stiffness, WOMAC, and overall improvement) was only significant for those patients presenting only minor loss of medial and lateral joint space..$^{28}$

\section{Arthroscopic lavage and surgery}

In theory, lavage of the joint (through a large needle or by arthroscopy) removes debris such as microscopic or macroscopic fragments of cartilage or calcium phosphate crystals that may induce synovitis, a likely source of pain. Tidal irrigation is a similar process but using only one entry site.

Arthroscopic debridement consists of smoothing rough, fibrillated articular and meniscal surfaces, shaving tibialspine osteophytes that interfere with the motion of the joint, and removing inflamed synovium. A study showed that needle lavage is comparable with arthroscopic debridement with lavage, except in patients with meniscal tears. ${ }^{29}$

\section{Level of evidence of symptomatic efficacy}

In RCTs without sham treatment in the control group, those who underwent lavage reported greater improvement in knee pain than those who received usual medical management alone. ${ }^{30}$ However, possibly, the benefits were due to placebo effect. Three trials in which needles were inserted into control knees evaluated lavage. One compared lavage with a large or small volume of saline: the authors reported no significant improvement in pain in either group. ${ }^{31}$ The second trial by Ravaud et al compared joint lavage, IA steroid injection, and IA placebo, alone and in combination, in patients with symptomatic knee OA. ${ }^{15}$ Compared with placebo, both treatments significantly relieved pain: cortivazol provided short term relief (up to week 4), and lavage provided persistent relief (up to week 24). Neither treatment improved functional impairment. An additive effect of lavage and IA steroid injection was observed. The third publication, a recent double blind trial by Bradley et al, compared the effectiveness of lavage (1 litre) with a sham irrigation procedure on 180 subjects, with a 12 month follow up. ${ }^{32}$ Although the study groups were otherwise comparable, the baseline WOMAC pain and physical functioning scores were higher (worse) in the placebo group. After adjustment for baseline, no differences between the effects of lavage and sham irrigation were found.

The efficacy of arthroscopy is not much better documented. Recently, Moseley et al reported a randomised, placebo controlled, double blind trial of arthroscopy in OA of the knee. $^{33}$ Patients with OA of the knee $(n=180)$ were randomly assigned to receive arthroscopic debridement, arthroscopic lavage ( 10 litres of fluid), or placebo surgery (consisting of skin incisions and a simulated debridement without insertion of the arthroscope). Outcomes (three scales for pain, two for function, and one objective test of walking and stair climbing) were evaluated at multiple points over 24 months. At no point did either of the intervention groups report less pain or better function than the placebo group.

Time to onset of efficacy and carryover effect

Onset of efficacy is rapid: less than 1 week. In those trials showing a positive effect of lavage or arthroscopy, efficacy is maintained for up to 6 months.

\section{Predisposing factors of response}

For lavage, patient selection may have a significant effect on the response. Those patients with evidence of calcium pyrophosphate deposition disease have variously been described as being either more or less responsive to joint irrigation. ${ }^{31} 34{ }^{35}$ High degrees of radiographic severity of OA have been associated with a poorer response to lavage, ${ }^{30}$ and a larger volume of removed debris has been associated with better response. $^{36}$

For the subgroup of knees with loose bodies or flaps of meniscus or cartilage that are causing mechanical symptoms, especially locking, catching, or the joint to give way, there is a consensus that arthroscopic removal of these unstable tissues improves joint function and alleviates symptoms. On the other hand, meniscal tears are extremely prevalent in knees with $\mathrm{OA}$, and their relation to knee pain is questionable at best. In joints without specific mechanical symptoms, repairing stable meniscal tears is probably not indicated.

\section{Other IA treatments \\ Synoviorthesis}

Radioactive injections (isotope synoviorthesis) and osmic acid (chemical synoviorthesis) have been used for many years in inflammatory diseases. Their place is probably limited in $\mathrm{OA}$, and there are no RCTs evaluating them in this indication. One open study reported results for 54 patients (76 knees treated with yttrium-90 and 16 with osmic acid). ${ }^{37}$ At 6 months $22-34 \%$ of results were satisfactory or very satisfactory.

\section{Experimental treatments}

\section{IA methotrexate or rifampicin}

One study of 82 patients compared $20 \mathrm{mg}$ IA triamcinolone hexacetonide alone with its combination with $50 \mathrm{mg}$ IA methotrexate or $600 \mathrm{mg}$ IA rifampicin. ${ }^{38}$ Pain (as measured by area under the curve and duration of improved pain scores) was significantly better in the triamcinolone+rifampicin group, but 11 of those 28 patients developed a flare of pain after injection.

\section{IA anti-tumour necrosis factor or interleukin 1 inhibitor} injections

Studies are being conducted in these fields in inflammatory diseases but are still very experimental. 


\section{STRUCTURAL EFFECTS OF IA TREATMENTS Intra-articular corticosteroids}

The effect of steroids on cartilage metabolism and progression of OA has been studied in a number of animal models, with conflicting results. In some models a chondroprotective effect was found, but others showed a possibly deleterious effect on cartilage. In a recent placebo controlled trial of repeated IA steroid injections every 3 months for up to 2 years, the primary outcome variable was radiological progression of joint space narrowing. ${ }^{16}$ After 2 years, no difference in loss of joint space over time was noted between the steroid and the placebo groups. Thus, no deleterious effects of the long term administration of IA steroids on the anatomical structure of the knee were noted.

Overall, there is little evidence of a deleterious effect on cartilage, and reports of a Charcot-like accelerated joint destruction after steroid injection in human hip OA may reflect the disease itself rather than the treatment. Any effect on bone metabolism, as judged by biochemical markers, appears to be transient and mild. ${ }^{39}$ As for in vivo and in vitro animal models, which suggest a possible disease modifying effect, they must be viewed with caution because of the limitations of comparing animals with humans, and inflammatory and non-inflammatory disease.

\section{Hyaluronic acid injections}

Potential structure modifying effects of HA in OA have been suggested in animal models, but with conflicting results. ${ }^{40}$ Limited studies in humans have been performed. Listrat et al reported in a pilot controlled, randomised study of 36 patients with knee medial OA that those who received three series of three Hyalgan injections at 3 month intervals showed less progression of the disease 1 year later, as judged by arthroscopy, than controls who received conventional treatment but no hyaluronan injections. ${ }^{41}$ The HA group also scored higher for quality of life and reduced their use of NSAIDs during the study period. However, the patient numbers were small. Recently, 408 patients assigned randomly to receive three courses of three IA injections of Hyalgan or placebo were evaluated radiologically after one year. ${ }^{42}$ Analysis showed no difference in medial femorotibial joint space width narrowing between the two groups in the entire population, but among the patients with less severe disease (baseline joint space width $\geqslant 4.6 \mathrm{~mm}$ ), the subgroup treated with Hyalgan showed significantly less narrowing.

\section{CONCLUSION}

\section{Intra-articular corticosteroids}

Intra-articular corticosteroids are a fast acting symptomatic drug in OA. There is evidence that they do not induce long term deleterious effects on cartilage. Owing to the short lived effect on pain of IA steroids (1-4 weeks), the frequent need for repeated injections limits the usefulness of this agent in long term management of OA. Thus, their use should be logically focused on short term treatment of disease flaresthat is, exacerbation of pain, nocturnal pain, and effusion.

\section{Hyaluronan}

Hyaluronan acts as a symptomatic slow acting drug with a delayed onset of efficacy of 2-5 weeks and a long lived benefit (4-12 months) on pain and function. To date there are insufficient data to support the hypothesis that hyaluronan might be a structure modifying agent. Hyaluronan treatment seems particularly indicated in painful knee OA, radiologically moderate, with no or mild effusion.

The planned formal meta-analysis of both IA corticosteroids and viscosupplementation for knee OA by the Cochrane Collaboration will clarify the level of evidence supporting the symptomatic efficacy of these IA treatments.

\section{Lavage and debridement}

For most patients with knee OA, lavage and debridement are probably not as efficient a treatment as once was hoped. The exact place of lavage in knee OA remains to be established; we reserve arthroscopy for patients who present specific mechanical symptoms related to unstable meniscus flaps.

Up to now, IA treatments in OA were prescribed for their symptomatic efficacy-that is, these treatments were performed on patients with painful knees. If the structural effects of IA treatments are demonstrated, the aim will then be to treat preventively asymptomatic patients. That decision will certainly be much harder to take and will have to be discussed with the patient after clear information is given about the objectives and available means.

\section{Authors' affiliations}

L Gossec, M Dougados, René Descartes University, Cochin Hospital, Rheumatology B Department, Paris, France

\section{REFERENCES}

1 ACR. American College of Rheumatology subcommittee on osteoarthritis guidelines. Recommendations for the medical management of osteoarthritis of the hip and knee: 2000 update Arthritis Rheum 2000;43:1905-15.

2 Pendleton A, Arden N, Dougados M, Doherty M, Bannwarth B, Biilsma JW, et al. EULAR recommendations for the management of knee osteoarthritis: report of a task force of the Standing Committee for International Clinical Studies Including Therapeutic Trials (ESCISIT). Ann Rheum Dis 2000;59:936-44.

3 Hochberg MC, Perlmutter DL, Hudson Jl, Altman RD. Preferences in the management of osteoarthritis of the hip and knee: results of a survey of community based rheumatologists in the United States. Arthritis Care Res 1996;9:170-6.

4 Creamer P. Intra-articular corticosteroid treatment in osteoarthritis. Curr Opin Rheumatol 1999;11:417-21.

5 Ayral X. Injections in the treatment of osteoarthritis. Best Pract Res Clin Rheumatol 2001;15:609-26.

6 Miller JH, White J, Norton TH. The value of intra-articular injections in osteoarthritis of the knee. J Bone Joint Surg Br 1958;4013:636-43.

7 Wright V, Chandler GN, Morison RA, Hartfall SJ. Intra-articular therapy in osteoarthritis. Comparison of hydrocortisone acetate and hydrocortisone tertiary-butylacetate. Ann Rheum Dis 1960;19:257-61.

8 Cederlof S, Jonson G. Intra-articular prednisolone injection for osteoarthritis of the knee. Acta Chir Scand 1966;132:532-6.

9 Friedman DM, Moore ME. The efficacy of intra-articular steroids in osteoarthritis: a double blind study. J Rheumatol 1980;7:850-6.

10 Dieppe PA, Sathapayavongs B, Jones HE, Bacon PA, Ring EFJ. Intra-articular steroids in osteoarthritis. Rheumatol Rehabil 1980;19:212-17.

11 Valtonen E. Clinical comparison of triamcinolone hexacetonide and bethamethasone in the treatment of osteoarthritis of the knee joint. Scand J Rheumatol Suppl 1981;41:1-7.

12 Sambrook PN, Champion GD, Browne CD, Cairns D, Cohen ML, Day RO. Corticosteroid injection for osteoarthritis of the knee: peripatellar compared to intra-articular route. Clin Rheumatol 1989;7:609-13.

13 Gaffney K, Ledingham J, Perry JD. Intra-articular triamcinolone hexacetonide in knee osteoarthritis: factors influencing the clinical response. Ann Rheum Dis 1995; 54:379-81.

14 Jones A, Doherty M. Intra-articular corticosteroids are effective in osteoarthritis but there are no clinical predictors of response. Ann Rheum Dis 1996;55:829-32.

15 Ravaud P, Moulinier L, Giraudeau B, Ayral X, Guerin C, Noel E, et al. Effects of joint lavage and steroid injection in patients with osteoarthritis of the knee: results of a multicenter, randomized, controlled trial. Arthritis Rheum 1999;42:475-82.

16 Raynauld JP, Buckland-Wright C, Ward R, Choquette D, Haraoui B, MartelPelletier J, et al. Safety and efficacy of long-term intraarticular steroid injections in osteoarthritis of the knee: a randomized, double-blind, placebocontrolled trial. Arthritis Rheum 2003;48:370-7.

17 Kirwan JR, Rankin E. Intra-articular therapy in osteoarthritis. Baillieres Clin Rheumatol 1997;11:769-94.

18 Towheed TE, Hochberg MC. A systematic review of randomized, controlled trials of pharmacological therapy in osteoarthritis of the knee. Semin Arthritis Rheum 1997;26:755-70.

19 Plant MJ, Borg AA, Dziedzik K, Saklatvala J, Dawes PT. Radiographic patterns and response to corticosteroid hip injection. Ann Rheum Dis 1997;56:476-80.

20 Weitoft T, Uddenfeldt P. Importance of synovial fluid aspiration when injecting intra-articular corticosteroids. Ann Rheum Dis 2000:59:233-5.

21 Jones A, Regan M, Ledingham J, Pattrick M, Manhire A, Doherty M. Importance of placement of intra-articular steroid injections. $B M J$ 1993;307:1329-30.

22 Brandt KD, Block JA, Michalski JP, Moreland LW, Caldwell JR, Lavin PT. Efficacy and safety of intraarticular sodium hyaluronate in knee osteoarthritis. Orthovisc Study Group. Clin Orthop 2001;385:130-43. 
23 Leardini G, Perbellini A, Franceschini M, Mattara L. Intra-articular injections of hyaluronic acid in the treatment of painful shoulder. Clin Ther 1988; 10:521-6.

24 Brocq O, Tran G, Breuil V, Grisot C, Flory P, Euller-Ziegler L. Hip osteoarthritis: short-term efficacy and safety of viscosupplementation by hylan G-F 20. An open-label study in 22 patients. Joint Bone Spine 2002;69:388-91.

25 Migliore A, Martin LS, Alimonti A, Valente C, Tormenta S. Efficacy and safety of viscosupplementation by ultrasound-guided intra-articular injection in osteoarthritis of the hip. Osteoarthritis Cartilage 2003;11:305-6.

26 Altman RD, Moskowitz R. Intraarticular sodium hyaluronate (Hyalgan) in the treatment of patients with osteoarthritis of the knee: a randomized clinical trial. Hyalgan Study Group. J Rheumatol 1998;25:2203-12.

27 Lussier A, Cividino AA, McFarlane CA, Olszynski WP, Potashner WJ, De Medicis R. Viscosupplementation with hylan for the treatment of osteoarthritis: findings from clinical practice in Canada. J Rheumatol 1996;23:1579-85.

28 Toh EM, Prasad PS, Teanby D. Correlating the efficacy of knee viscosupplementation with osteoarthritic changes on roentgenological examination. Knee 2002;9:321-30

29 Chang RW, Falconer J, Stulberg SD, Arnold WJ, Manheim LM, Dyer AR. A randomized, controlled trial of arthroscopic surgery versus closed-needle joint lavage for patients with osteoarthritis of the knee. Arthritis Rheum 1993;36:289-96.

30 lke RW, Arnold WJ, Rothschild EW, Shaw HL. Tidal irrigation versus conservative medical management in patients with osteoarthritis of the knee: a prospective randomized study. Tidal Irrigation Cooperating Group. J Rheumatol 1992;19:772-9.

31 Kalunian KC, Moreland LW, Klashman DJ, Brion PH, Concoff AL, Myers S, et al. Visually-guided irrigation in patients with early knee osteoarthritis: a multicenter randomized, controlled trial. Osteoarthritis Cartilage 2000;8:412-18.
32 Bradley JD, Heilman DK, Katz BP, Gsell P, Wallick JE, Brandt KD. Tidal irrigation as treatment for knee osteoarthritis: a sham-controlled, randomized, double-blinded evaluation. Arthritis Rheum 2002;46:100-8.

33 Moseley JB, O'Malley K, Petersen NJ, Menke TJ, Brody BA, Kuykendall DH, et al. A controlled trial of arthroscopic surgery for osteoarthritis of the knee. N Engl J Med 2002;347:81-8.

$34 \mathrm{O}^{\prime}$ Connor RL. The arthroscope in the management of crystal-induced synovitis of the knee. J Bone Joint Surg Am 1973;55:1443-9.

35 Bennett RM, Lehr JR, McCarty DJ. Crystal shedding and acute pseudogout. An hypothesis based on a therapeutic failure. Arthritis Rheum 1976;19:93-7.

36 Rangiwala MA, Michalska M, Block JA. Pain improvement and quantity of articular debris after arthroscopy for osteoarthritis of the knee [abstract]. Arthritis Rheum 1995;38(suppl 9):S240.

37 Hilliquin P, Le Devic P, Menkes CJ. Comparaison de l'efficacité des synoviorthèses et du lavage articulaire dans la gonarthrose avec épanchement. Rev Rhum (Ed Fr) 1996;63:99-108.

38 Blyth T, Stirling A, Coote J, Land D, Hunter JA. Injection of the rheumatoid knee: does intra-articular methotrexate or rifampicin add to the benefits of triamcinolone hexacetonide? Br J Rheumatol 1998;37:770-2.

39 Emkey RD, Lindsay R, Lyssy J, Weisberg J, Dempster D, Shen V. The systemic effect of intra-articular administration of corticosteroid on markers of bone formation and bone resorption in patients with rheumatoid arthritis. Arthritis Rheum 1996;39:277-82.

40 Brandt KD, Smith GN, Simon LS. Intraarticular injection of hyaluronan as treatment for knee osteoarthritis. What is the evidence? Arthritis Rheum 2000;43: 1192-203.

41 Listrat V, Ayral X, Patarnello F, Bonvarlet JP, Simonnet J, Amor B, et al. Arthroscopic evaluation of potential structure modifying activity of hyaluronan (Hyalgan) in osteoarthritis of the knee. Osteoarthritis Cartilage 1997;5:153-60.

42 Jubb RW, Piva S, Beinat L, Dacre J, Gishen P, on behalf of the UK Hyalgan Study Group. Structure modification in osteoarthritis with intra-articular sodium hyaluronate of mon. $500-730 \mathrm{kDa}$ [abstract]. Ann Rheum Dis $2001 ; 60$ (suppl 1):46. 